\title{
Efeito da Montmorilonita Organifílica na Compatibilização e nas Propriedades Morfológicas, Mecânicas e Térmicas de Blendas de PA6/ PEBD
}

\author{
Paulo Henrique da Silva Leite Coelho, Ana Rita Morales \\ Departamento de Engenharia de Materiais e Bioprocessos, Faculdade de Engenharia Química, UNICAMP
}

\begin{abstract}
Resumo: Blendas imiscíveis de poliamida 6 e polietileno de baixa densidade foram preparadas com e sem a presença de polietileno enxertado com anidrido maleico como compatibilizante. Montmorilonita organofílica foi incorporada nas blendas por intercalação do fundido. Análises morfológicas e estruturais apresentaram boa dispersão da argila, com a obtenção de estruturas intercaladas e esfoliadas. A separação de fases foi observada nas amostras, e tanto o compatibilizante como a argila causaram redução no tamanho dos domínios. Esta estrutura proporcionou uma melhora significativa nas propriedades mecânicas das blendas, revelando o efeito de reforço causado pela argila. O módulo elástico e a tensão máxima aumentaram em até $300 \%$ e 100\%, respectivamente. O efeito da compatibilização da argila foi positivo. Pelas análises de DSC pode-se observar o surgimento de um pico na região de fusão da PA6 atribuído à formação de uma nova fase cristalina devido à presença de argila.
\end{abstract}

Palavras-chave: Nanocompósitos, blendas, montmorilonita, polietileno, poliamida.

\section{The Effect of Organophilic Montmorillonite on Compatibilization, Morphology and Mechanical and Thermal Properties of PA6/ LDPE Blends}

\begin{abstract}
Immiscible blends of polyamide 6 and low density polyethylene were prepared with and without maleic anhydride grafted polyethylene used as a compatibilizer. Organophilic montmorillonite was incorporated in the blends by melt intercalation. Morphological and structural analysis showed good clay dispersion with partially exfoliated and intercalated structures. Phase separation was observed and domains size reduction was induced by the clay and the compatibilizer. Improvement on mechanical properties of compounds was observed, showing the reinforcing effect caused by the clay. Elastic modulus and tensile strength have increased up to $300 \%$ and $100 \%$, respectively. The clay showed a positive effect on compatibilization. DSC analysis revealed a new melting peak for PA6 assigned to a new crystalline phase due the clay effect.
\end{abstract}

Keywords: Nanocomposites, blends, montmorillonite, polyethylene, polyamide.

\section{Introdução}

O desenvolvimento de nanocompósitos poliméricos, caracterizados pela dispersão de cargas com dimensões nanométricas em resinas, representa um dos últimos passos em tecnologia de polímeros, sendo uma alternativa aos compósitos convencionais e blendas poliméricas.

A nanocarga mais empregada na preparação de nanocompósitos é a argila montmorilonita (MMT) e tem sido utilizada com diversas matrizes poliméricas ${ }^{[1-7]}$ incluindo-se, mais recentemente as blendas ${ }^{[8-10]}$. Destacase um grande avanço nas pesquisas com blendas e nanoargilas nas instituições brasileiras ${ }^{[11-13]}$ demonstrando principalmente o comportamento mecânico e reológico para estes materiais. Já os estudos da capacidade de compatibilização das argilas organofílicas em blendas imiscíveis não foram encontrados na literatura nacional e têm sido pouco citados na literatura ${ }^{[14,15]}$.

Uma blenda compatível de poliamida e polietileno seria uma alternativa interessante devido às diferentes propriedades destes polímeros. As poliamidas são utilizadas em embalagens barreira aos gases orgânicos e apresentam alta resistência à tração, mas são sensíveis ao entalhe em ensaios de resistência ao impacto e apresentam baixa estabilidade dimensional devido à alta absorção de água. Já os polietilenos apresentam uma alta resistência ao impacto, boa processabilidade, porém alta permeabilidade aos solventes orgânicos e gases ${ }^{[16]}$.

Embalagens flexíveis são muitas vezes compostas por camadas de Poliamida 6 (PA6) e de Polietileno de baixa densidade (PEBD) para a obtenção de filmes de alta barreira e com boas propriedades de soldagem. No entanto, a reutilização destes filmes no processo de reciclagem interna das empresas, ou mesmo das embalagens descartáveis, é de grande dificuldade pela incompatibilidade destas resinas. A possibilidade de reutilização dos chamados refiles nas próprias embalagens é importante não somente para a redução dos custos das embalagens, como também no aspecto ambiental, pela redução de resíduos.

Vários autores desenvolveram seus estudos na compatibilização de blendas de poliamida e polietileno com a inserção de diferentes compatibilizantes, com o objetivo de estudar a influência destes agentes nas

Autor para correspondência: Paulo Henrique da Silva Leite Coelho, Faculdade de Engenharia Química, Universidade Estadual de Campinas - UNICAMP, Av. Albert Einstein, 500, Cidade Universitária Zeferino Vaz, CEP 13083-852, Campinas, SP, Brasil, e-mail: piyke.coelho@gmail.com 
propriedades térmicas, mecânicas e morfológicas das blendas ${ }^{[17-21]}$. Embora o uso de compatibilizantes tenha mostrado eficiência na obtenção de propriedades interessantes nestes sistemas, a abordagem associada ao uso de nanocargas é mais recente e promissora. São relatados melhores resultados na estabilidade térmica, ductibilidade e dureza para blendas de $\mathrm{PA} 6 / \mathrm{PP}^{[22]}$, maior resistência à foto-oxidação para $\mathrm{PA6} / \mathrm{PEBD}^{[9]}$ e efeitos de reforço por restrição na mobilidade de segmentos de cadeia para PA6/PE-g-MA ${ }^{[10]}$ sempre associados às alterações na morfologia promovidas pela presença das nanocamadas da argila.

O objetivo deste trabalho é o de estudar o efeito de compatibilização da argila organofílica nas blendas de PA 6 e PEBD. Realizou-se a comparação dos sistemas com a presença, ou não, do agente compatibilizante em diferentes concentrações de argila, observando-se as propriedades mecânicas, térmicas, bem como alterações na cristalinidade e na morfologia.

\section{Experimental}

\section{Materiais}

O polietileno utilizado neste trabalho foi o PEBD G 803 da Braskem em pó, com índice de fluidez (MFI) de $30 \mathrm{~g} / 10 \mathrm{~min}$, densidade de $0,918 \mathrm{~g} / \mathrm{cm}^{3}$. A poliamida utilizada foi a PA 6 MAZMID B 260 da Mazzafero em pó, com massa molar numérica média (Mn) de $18918 \mathrm{~g} / \mathrm{mol}$, massa molar ponderal média (Mw) de $37835 \mathrm{~g} / \mathrm{moL}$ e densidade de $1,14 \mathrm{~g} / \mathrm{cm}^{3}$. O agente de compatibilização utilizado foi o polietileno enxertado com anidrido maleico, AMPLIFYTM GR 216 (PE-gAM), em grânulos, polímero funcional da Dow, MFI de $1,3 \mathrm{~g} / 10 \mathrm{~min}$, densidade de $1,14 \mathrm{~g} / \mathrm{cm}^{3}$ e teor de anidrido maleico de $0,5-1,0 \%$. A argila empregada na preparação dos nanocompósitos foi uma montmorilonita modificada organicamente com octadecil amônio, Nanomer I.30T da Nanocor (MMT) em pó. A Nanomer I.30T é uma argila com alta compatibilidade com a PA 6, projetada especificamente para a extrusão, e proporciona um melhor desempenho com baixas concentrações, entre 3\% a $8 \%$ em peso $^{[23]}$.

\section{Preparação dos nanocompósitos}

Devido à diferença na concentração relativa entre os componentes, foi necessária uma pré-mistura entre os materiais para garantir boa homogeneização nas composições. Os materiais sólidos foram pré-misturados em um misturador tipo "Henschell” da marca Mecanoplast, operando em uma velocidade de pá de $1700 \mathrm{rpm}$ por aproximadamente 3 minutos à temperatura ambiente. Posteriormente, as misturas foram processadas por fusão em uma extrusora dupla rosca co-rotante de $25 \mathrm{~mm}$, Werner Pfleiderer, Modelo ZSK 25 Mega Compounder, $\mathrm{L} / \mathrm{D}=36$, a $220 \mathrm{rpm}$ e com perfil de temperaturas de 180 , 220, 230, 240 e $240{ }^{\circ} \mathrm{C}$. A alimentação foi feita por um equipamento Brabender FW33 com rosca espiral de 30 mm de diâmetro, que inseriu os materiais na extrusora a uma velocidade constante de $10 \mathrm{rpm}$. Na Tabela 1 são apresentadas as composições estudadas.
Tabela 1. Concentrações (pcr) dos nanocompósitos.

\begin{tabular}{lcccc}
\hline \multicolumn{1}{c}{ Amostras } & PEBD & PA6 & PE-g-AM & Argila \\
\hline PEBD/PA6/3Argila & 50 & 50 & 0 & 3 \\
PEBD/PA6/3Argila/3AM & 50 & 50 & 3 & 3 \\
PEBD/PA6/6Argila & 50 & 50 & 0 & 6 \\
PEBD/PA6/6Argila/3AM & 50 & 50 & 3 & 6 \\
\hline
\end{tabular}

\section{Caracterização das propriedades}

As análises de Microscopia Eletrônica de Varredura (MEV) foram realizadas para avaliar a morfologia dos nanocompósitos. As amostras foram injetadas e fraturadas criogenicamente, recobertas com uma liga de ouro-paládio, e analisadas com o microscópio Leo 440i, trabalhando em uma corrente de 100 p $\AA$ e tensão de $20 \mathrm{~kW}$

A análise de Microscopia Eletrônica de Transmissão (MET) foi utilizada para avaliar o grau de intercalação e esfoliação da argila na matriz polimérica. As amostras injetadas foram crioultramicrotomadas a $\quad-60 \quad{ }^{\circ} \mathrm{C}$ com $60 \mathrm{~nm}$ de espessura em um micrótomo Leica, Reichert Ultracut-E, com faca de diamante Diatome. O microscópio eletrônico utilizado foi o Philips CM 120, operando a uma voltagem de aceleração de $120 \mathrm{kV}$.

As análises de difração de raios-X (DRX) foram realizadas com equipamento Shimadzu XRD 7000, com varredura de $1,5^{\circ}$ a $50^{\circ}$ em $2 \theta$, com radiação de $\operatorname{Cuk}_{\alpha} \lambda=1,54 \AA$, potência no tubo de $40 \mathrm{kV}$ e corrente de $30 \mathrm{~mA}$.

As transições térmicas foram estudadas por calorimetria diferencial exploratória (DSC) com equipamento Mettler Toledo DSC822e/500, em uma faixa de temperatura de $-60{ }^{\circ} \mathrm{C}$ a $300{ }^{\circ} \mathrm{C}$, taxa de aquecimento de $10{ }^{\circ} \mathrm{C} / \mathrm{min}$, sob atmosfera de Nitrogênio $\left(\mathrm{N}_{2}\right)$, com fluxo de $50 \mathrm{~mL} / \mathrm{min}$ em amostras granuladas após processo de extrusão.

Os ensaios de resistência à tração foram realizados de acordo com a norma ASTM D-638 em uma Máquina Universal de Ensaios, Emic DL2000, com célula de carga de $5000 \mathrm{~N}$ e velocidade da tração de $50 \mathrm{~mm} /$ min. Os resultados foram obtidos a partir de uma média de 5 corpos de prova injetados em equipamento Pavan Zanetti NFN 150P, com perfil de temperatura de 210 , 230 e $240{ }^{\circ} \mathrm{C}$, temperatura de molde de $30{ }^{\circ} \mathrm{C}$ e tempo de injeção de $6 \mathrm{~s}$.

\section{Resultados e Discussão}

\section{Microscopia Eletrônica de Varredura}

$\mathrm{Na}$ Figura 1 são apresentadas as fotomicrografias para a blenda e nanocompósitos.

A blenda de PEBD/PA, Figura 1a, apresenta-se com fases distintas, os domínios são grandes e bem definidos, esféricos, com diâmetro aproximado de $18 \mu \mathrm{m}$, e a aderência interfacial entre as fases é fraca. Com a inserção do PE-g-AM, Figura 1b, ocorre diminuição dos domínios, com uma melhoria significativa na dispersão destes, evidenciando um comportamento típico, descrito na literatura, de blendas imiscíveis compatibilizadas ${ }^{[18,24,25]}$. 


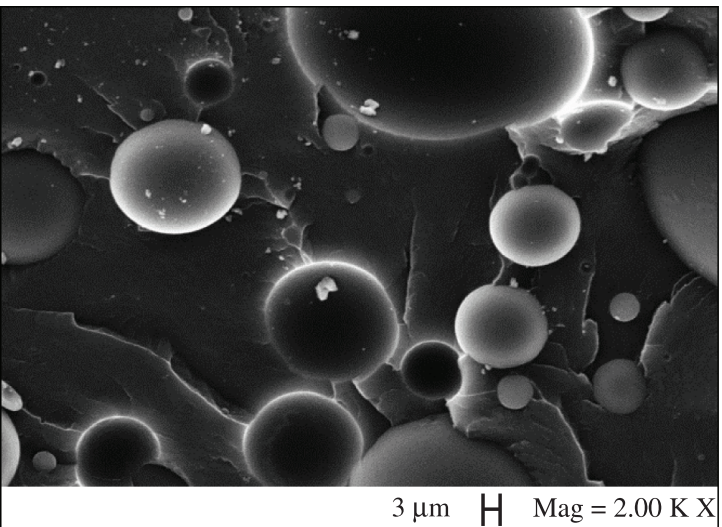

(a)

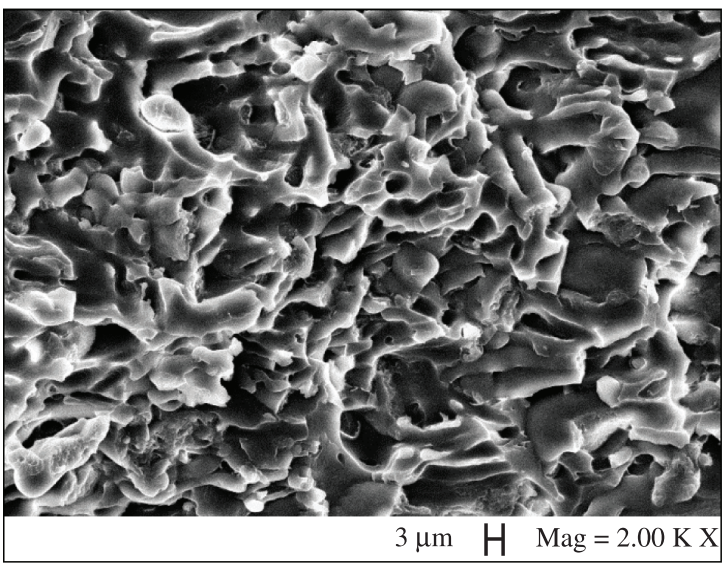

(c)

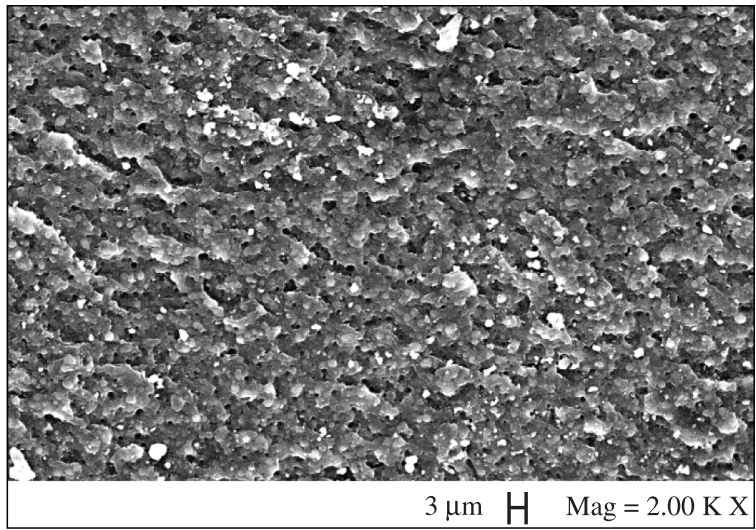

(b)

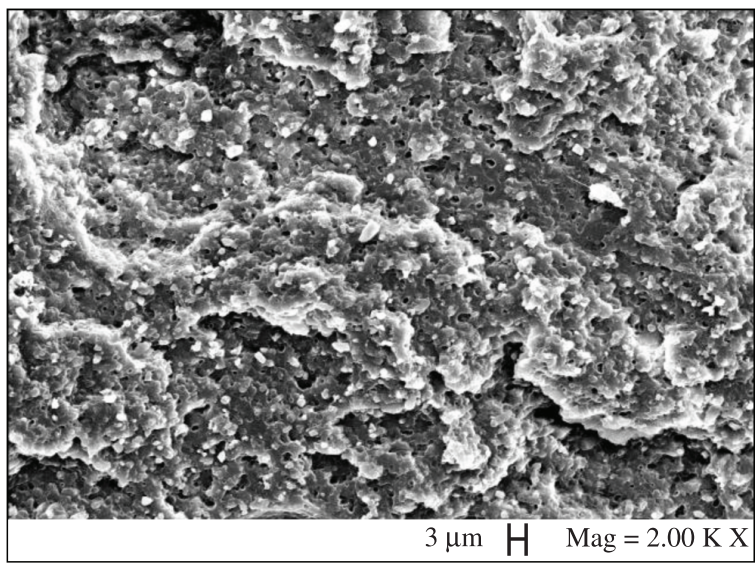

(d)

Figura 1. Fotomicrografias obtidas por MEV: (a) PEBD/PA6: 50/50; (b) PEBD/PA6/AM: 50/50/3; (c) PEBD/PA6/Argila: 50/50/6; (d) PEBD/PA6/Argila/AM: 50/50/6/3.

A morfologia resultante pela incorporação da argila, Figura 1c, é caracterizada pela deformação dos domínios e a redução do tamanho das fases distintas. Esta diminuição nos domínios devido à ação da argila também foi relatada em outros estudos ${ }^{[26-28]}$ e foi explicada por diferentes teorias. As teorias que descrevem este efeito o analisam dependendo se as camadas de argila estão localizadas na fase dispersa, na fase contínua ou na interface. Uma possibilidade de alteração nos domínios é a localização das nanocamadas esfoliadas de argila agindo como barreiras físicas, dificultando a coalescência das gotículas da fase precipitada ${ }^{[29]}$. Outra explicação está relacionada com o aumento da viscosidade da matriz polimérica na presença de argila, que pode influenciar na transferência de tensão melhorando a dispersão e a distribuição dos domínios e, também pode dificultar a coalescência dos domínios durante o processamento ${ }^{[28]}$.

A morfologia dos nanocompósitos com PE-g-MA, Figura 1d foi similar à estrutura da respectiva blenda, Figura 1b, destacando o efeito do agente compatibilizante. Scafarro et al. ${ }^{[15]}$ também obtiveram em seus estudos morfologia mais homogênea e com menores domínios em nanocompósitos de PEAD/PA6/argila com a inserção do agente compatibilizante. Associa-se este efeito à supressão da coalescência dos domínios causado pelas nanocamadas da argila e não pela indução da quebra dos domínios da fase dispersa ${ }^{[19]}$.

As fotomicrografias revelaram homogeneidade nos nanocompósitos, sem a presença de aglomerados, indicando que houve boa dispersão da argila na matriz, mas não permite dizer o grau de esfoliação ou intercalação obtido, e para isso foram realizadas análises de MET.

\section{Microscopia Eletrônica de Transmissão}

A Figura 2 ilustra as fotomicrografias obtidas por MET dos nanocompósitos com e sem a presença do agente compatibilizante. Observa-se nas Figuras 2a, b, para o nanocompósito sem a presença de agente compatibilizante, que a argila localizase preferencialmente em algumas regiões, como se circundando as regiões mais claras. Isto ocorre devido à sua compatibilidade com a PA6 ${ }^{[23]}$ e sugere que as regiões contínuas, mais escuras nas fotomicrografias, representem a fase rica em PA6. Observa-se também esfoliação das camadas da argila, com a presença de estruturas aglomeradas e intercaladas. Com a inserção do agente compatibilizante, Figuras 2c, d, a argila apresenta maior grau de esfoliação e não está preferencialmente localizada em uma das fases. Isto pode ser explicado pela ação do compatibilizante que é composto de grupos 


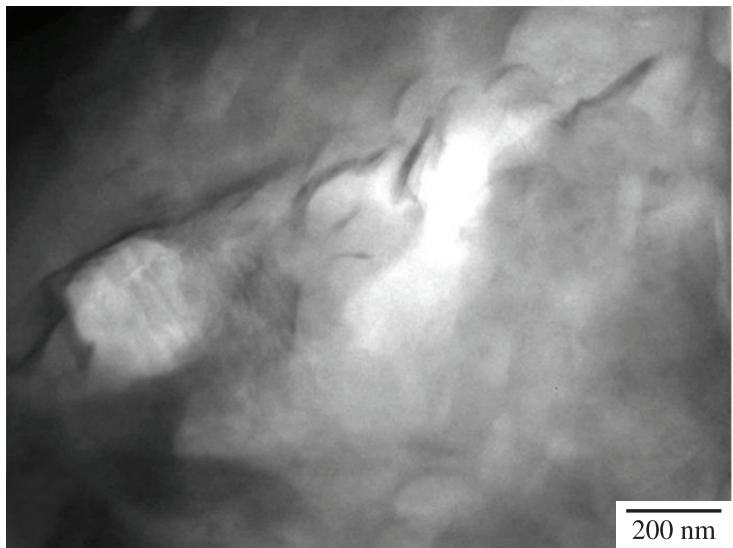

(a)

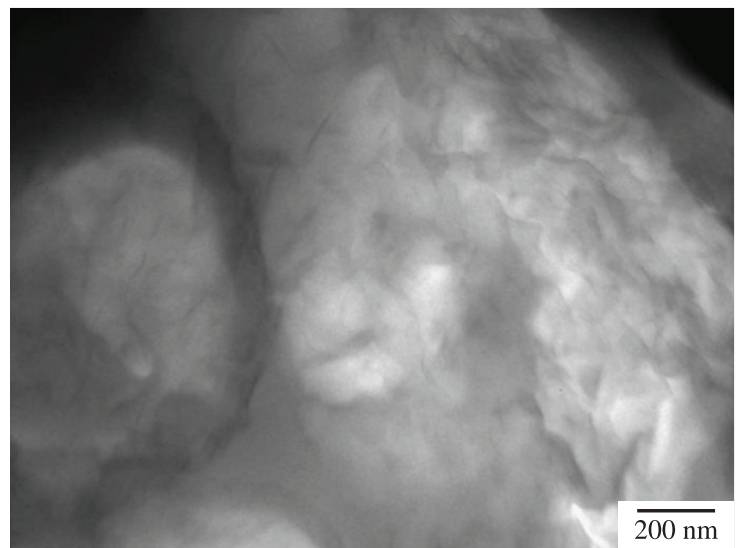

(c)

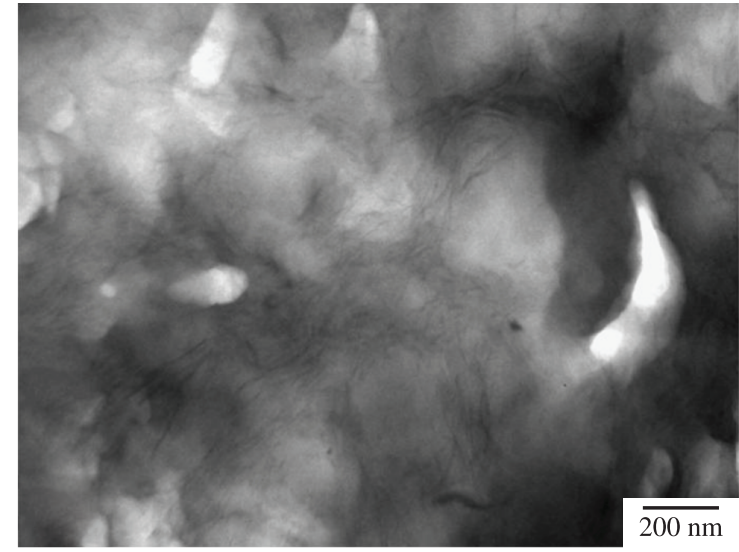

(b)

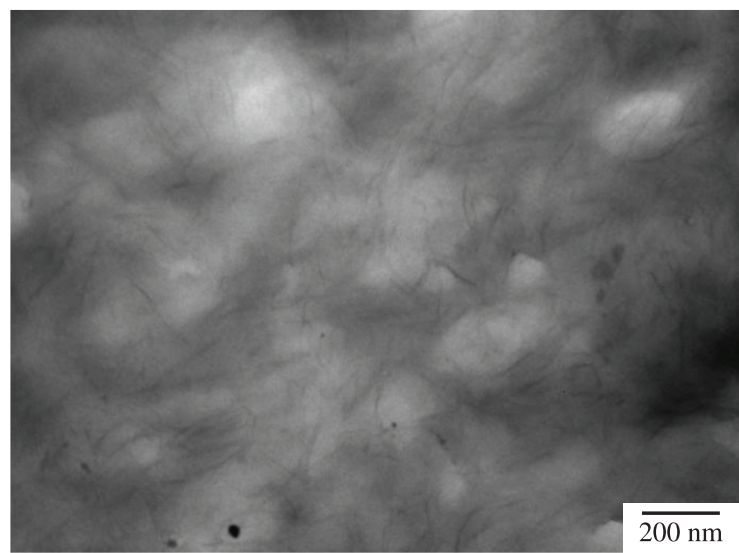

(d)

Figura 2. Fotomicrografias dos nanocompósitos obtidas por MET: (a) PEBD/PA6/Argila: 50/50/3 e (b) PEBD/PA6/Argila: 50/50/6, (c) PEBD/PA6/Argila/AM: 50/50/3/3 e (d) PEBD/PA6/Argila/AM: 50/50/6/3.

anidridos capazes de reagir com grupos finais amina da PA6, e por possuir segmentos de PE, que são miscíveis com a fase de polietileno ${ }^{[11]}$. Esta dupla compatibilidade do agente, somada à sua afinidade com a parte orgânica e polar da argila permite que a argila se disperse em ambas as fases da blenda. Estudos similares revelaram esfoliação e diminuição dos aglomerados de argila na presença de polietileno enxertado com anidrido maleico em matrizes de $\operatorname{PEBD}^{[30,31]}$.

\section{Difração de raios- $X$}

A Figura 3 apresenta os resultados de difração de raios-X obtidos para a argila Nanomer I.30T pura, e os nanocompósitos contendo 3 e 6 pcr de argila, com e sem a presença de 3 pcr do compatibilizante utilizado. Os dados restringem-se à faixa de $1,5^{\circ}$ a $10^{\circ} \mathrm{em} 2 \theta$, por ser a região de difração do plano 001 da argila.

A argila Nanomer I.30 T apresentou um pico de difração em $4,1^{\circ}$ que representa um espaçamento basal de 2,16 nm. Na análise do difratograma dos nanocompósitos observa-se um indício de intercalação das cadeias poliméricas entre as camadas de argila, pois um deslocamento do ângulo $2 \theta$ próximo a $2^{\circ}$, correspondente a um acréscimo no espaçamento basal de aproximadamente $1,5 \mathrm{~nm}$, foi encontrado em quase todas as composições. Apenas o nanocompósito com 3 pcr de argila e sem PE-g-MA apresentou a ausência de pico no difratograma. A princípio, a ausência do pico sugere a formação de estruturas esfoliadas, porém isto não foi confirmado nas análises de MET, Figura 2a, para a qual a fotomicrografia revelou estruturas esfoliadas e intercaladas das camadas da argila. Isto deve ter ocorrido pela falta de sensibilidade da técnica de difração de raios-X já que é baixa a concentração da argila.

\section{Propriedades mecânicas}

Na Tabela 2 são apresentados os resultados das propriedades mecânicas: módulo elástico $(\mathrm{E})$, resistência à tração máxima $\left(\sigma_{\mathrm{m}}\right)$ e deformação de ruptura $\left(\varepsilon_{\mathrm{r}}\right)$. Estas propriedades foram estudadas estatisticamente, analisando-se os efeitos de cada variável e suas interações. O software STATISTICA 7.0 Windows revelou que os efeitos apresentaram significância estatística, em um intervalo de confiança de $95 \%$, para as variáveis estudadas: concentração de argila, presença ou não do compatibilizante e a interação entre eles. A blenda pura, sem compatibilizante, não foi testada quanto às propriedades mecânicas por sua total incompatibilidade.

A blenda compatibilizada com o PE-g-AM apresentou propriedades intermediárias aos polímeros puros. Com a 


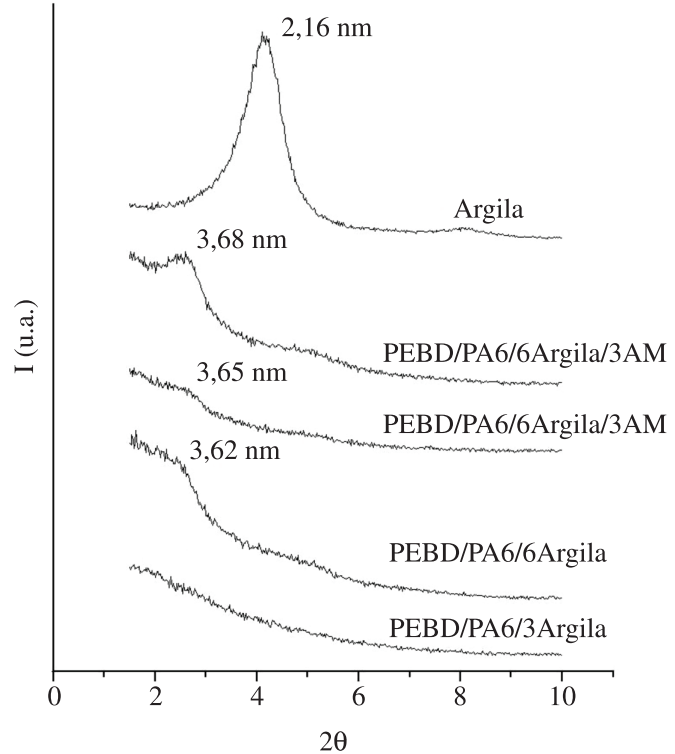

Figura 3. Difratogramas de raios- $X$ da argila e dos nanocompósitos.

Tabela 2. Propriedades mecânicas: módulo elástico (E), resistência à tração máxima $\left(\sigma_{\mathrm{m}}\right)$ e deformação de ruptura $\left(\varepsilon_{\mathrm{r}}\right)$.

\begin{tabular}{llll}
\hline \multicolumn{1}{c}{ Amostras } & \multicolumn{1}{c}{$\mathbf{E}(\mathbf{M P a})$} & $\sigma_{\mathrm{m}}(\mathbf{M P a})$ & \multicolumn{1}{c}{$\varepsilon_{\mathrm{r}}(\%)$} \\
\hline PEBD & $57 \pm 2$ & $9 \pm 1$ & $88 \pm 4$ \\
PA6 & $1084 \pm 23$ & $63 \pm 2$ & $131 \pm 85$ \\
PEBD/PA6/3AM & $162 \pm 6$ & $12 \pm 1$ & $10 \pm 1$ \\
PEBD/PA6/3Argila/3AM & $236 \pm 22$ & $18 \pm 1$ & $14 \pm 2$ \\
PEBD/PA6/6Argila/3AM & $487 \pm 17$ & $24 \pm 1$ & $7 \pm 1$ \\
PEBD/PA6/3Argila & $609 \pm 14$ & $24 \pm 1$ & $5 \pm 1$ \\
PEBD/PA6/6Argila & $651 \pm 17$ & $20 \pm 1$ & $4 \pm 1$ \\
\hline
\end{tabular}

inserção de argila observa-se significativo aumento no módulo elástico, E, destacando-se a concentração com 6 pcr de argila, sendo de $200 \%$ para blenda com PE-g-AM e de $300 \%$ para a blendas sem o PE-g-MA, o que evidencia o efeito de reforço, o aumento na rigidez e a importância da argila na compatibilização do nanocompósito formado. A presença do agente compatibilizante diminuiu o módulo de elasticidade em coerência com outros resultados da literatura $^{[15]}$.

A presença da argila também gerou aumento na resistência à tração máxima, $\sigma_{\mathrm{m}}$, para todas as composições, atingindo $100 \%$ para o nanocompósito sem compatibilizante com 3 pcr de argila, evidenciando novamente o papel da argila no reforço mecânico, confirmando comportamento similares já relatados ${ }^{[32]}$.

Atenção deve ser dada à análise da deformação de ruptura, $\varepsilon_{r}$. A incorporação da argila gerou um efeito significativo nesta propriedade. O comprometimento na deformação foi mais evidenciado na ausência do compatibilizante. Este decréscimo era esperado já que está diretamente associado ao acréscimo no valor de resistência, pois quanto maior a capacidade do material em suportar uma tensão imposta, menor será a deformação sofrida pelo mesmo.
A partir destes resultados pode-se considerar que a argila teve um efeito positivo no reforço da blenda para solicitações na região de deformação elástica, conferindo aumento de rigidez. Já na região de deformação plástica os defeitos de descontinuidade originários de aglomerados ou regiões de baixa compatibilidade causam ruptura precoce do material.

Como observado na análise de MET, a argila se dispersou nas duas fases da blenda onde o agente compatibilizante foi utilizado. Pode-se supor que parte do agente compatibilizante foi consumida na compatibilização da argila com o PEBD ficando insuficiente para atuar na compatibilização entre o PEBD e a PA6 na interface das fases. Estudos variandose o tipo e a quantidade do agente compatibilizante são necessários para a obtenção de sistemas com melhores propriedades.

\section{Análise da cristalinidade por DSC}

As curvas obtidas por DSC e os valores de temperatura de fusão $\left(\mathrm{T}_{\mathrm{m}}\right)$ dos polímeros e das fases são ilustradas na Figura 4.

Analisando-se as temperaturas de fusão dos materiais puros em relação à blenda, pode-se observar que a $T_{m}$ do PEBD sofre um pequeno aumento, em torno de $5{ }^{\circ} \mathrm{C}$. $\mathrm{O}$ mesmo comportamento ocorre analisando a $\mathrm{T}_{\mathrm{m}}$ da poliamida, que passa de uma temperatura de 221 para $225{ }^{\circ} \mathrm{C}$

Para os nanocompósitos não é observada mudança relevante na $\mathrm{T}_{\mathrm{m}}$ do PEBD. Porém, analisando-se a região de fusão da PÁ6 percebe-se a presença de um ombro no pico. Para a interpretação destes resultados considerou-se duas ocorrências, identificadas como $\mathrm{T}_{\mathrm{m} 1}$ e $\mathrm{T}_{\mathrm{m} 2}$. A $\mathrm{T}_{\mathrm{m} 1}$ corresponde ao pico principal característico de fusão da PA6 e está na faixa de $222{ }^{\circ} \mathrm{C}$. A $\mathrm{T}_{\mathrm{m} 2}$ corresponde ao surgimento de um pico de fusão que ficou na faixa dos $214-216^{\circ} \mathrm{C}$. Este pico, já relatado na literatura ${ }^{[18,33]}$ esta associado à formação da fase cristalina $\gamma$ na PA6. Este fenômeno foi discutido por alguns autores ${ }^{[34-36]}$, que relataram que a incorporação de argila organofílica em PA6 favorece a estrutura cristalina $\gamma$ em detrimento à fase $\alpha$ da PA6 pura. Isto ocorre devido à morfologia dos silicatos em camadas (tamanho, forma e distribuição) que causa um forte efeito sobre a estrutura e o processo de cristalização, onde a formação da fase $\gamma$ ocorre pela restrição nos dobramentos de cadeia, causando um distúrbio na formação dos cristais ${ }^{[36]}$.

A análise de DRX seria uma ótima ferramenta para comprovar o surgimento da fase $\gamma$ da PA6. Estas análises foram realizadas, porém por tratar-se de uma blenda a seguinte dificuldade foi encontrada: a região de ocorrência do pico relativo à fase $\gamma$ da PA6 está entre $21^{\circ} \mathrm{e}$ $22^{\circ}(2 \theta)$. Coincidentemente é a mesma região da difração do PEBD, com uma intensidade aproximadamente três vezes maior que o pico da PA6, o que acaba por sobrepor a região de interesse que evidenciaria a alteração das fases cristalinas da PA6. Dessa forma, tendo com base a literatura ${ }^{[35,36]}$, pode-se supor que os valores encontrados para as temperaturas de fusão da PA6 na presença da argila organofílica indicam que sua fase cristalina é composta, predominantemente, por cristais do tipo $\alpha$ 


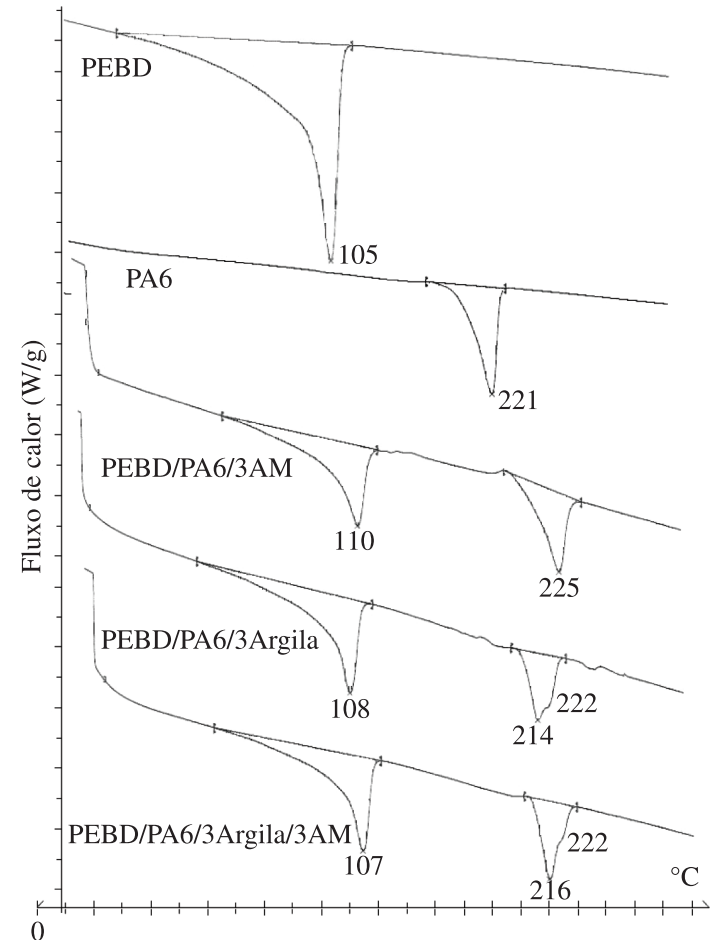

Figura 4. Curvas de DSC dos polímeros puros, blenda compatibilizada e nanocompósitos.

$\left(\mathrm{T}_{\mathrm{m} \alpha}=222{ }^{\circ} \mathrm{C}\right)$ e, em menor proporção, por cristais do tipo $\gamma\left(\mathrm{T}_{\mathrm{m} \gamma}=214-216^{\circ} \mathrm{C}\right)$.

\section{Conclusão}

O efeito da compatibilização da argila foi positivo resultando em uma redução nos domínios das fases presentes. As análises estruturais revelaram que a argila teve suas camadas parcialmente intercaladas e/ou esfoliadas em todos os nanocompósitos estudados. A argila teve um efeito importante na região elástica aumentando a rigidez, com valores de módulo elástico superiores em até $300 \%$. A resistência à tração máxima aumentou em até $100 \%$. Na região de deformação plástica, observou-se redução nos valores de deformação de ruptura. A argila teve um papel relevante nas propriedades térmicas dos nanocompósitos, pois com sua incorporação observouse o surgimento de um novo pico de fusão que sugere a formação da fase $\gamma$ durante o processo de cristalização da PA6.

\section{Agradecimentos}

Os autores agradecem ao CNPq pelo apoio financeiro.

\section{Referências Bibliográficas}

1. Wang, L.; Xie, X.; Su, S.; Feng, J. \& Wilkie, C. A. - Polym. Degrad. Stab., 95, p.572 (2010). http://dx.doi.org/10.1016/j. polymdegradstab.2009.12.012

2. Mishra, S.; Sonawane, S. S.; Shimpi, N. G.; Mishra, S.; Sonawane, S. S. \& Shimpi, N. G. - Appl. Clay Sci., 46, p.222 (2009). http://dx.doi.org/10.1016/j.clay.2009.07.024
3. Livi, S.; Jannick, D-R.; Pham, T. N. \& Gérard, J-F. - J. Colloid Interface Sci., 354, p.555 (2011).

4. Paiva, L. B. \& Morales, A. R. - Polímeros, 16, p.136 (2006).

5. Wang, J.; Du, X.; Yu, H.; Jiang, Z.; Liu, J. \& Tang, T. - Polymer, 50, p.5794 (2009). http://dx.doi.org/10.1016/j. polymer.2009.09.077

6. Vassiliou, A. A.; Chrissafis, K. \& Bikiaris, D. N. - Thermochim. Acta, 500, p.21 (2010). http://dx.doi. org/10.1016/j.tca.2009.12.005

7. Rodolfo Junior,A. \& Mei, L. H. I. -Polímeros, 19, p.1 (2009). http://dx.doi.org/10.1590/S0104-14282009000100006

8. Motamedi, P. \& Bagheri, R. - Mater. Des., 31, p.1776 (2010). http://dx.doi.org/10.1016/j.matdes.2009.11.013

9. Dintcheva, N. T.; Filippone, G.; La Mantia, F. P. \& Acierno, D. - Polym. Degrad. Stab., 95, p.527 (2010). http://dx.doi. org/10.1016/j.polymdegradstab.2009.12.021

10. Dayma, N. \& Satapathy, B. K. - Mater. Des., 33, p.510 (2012). http://dx.doi.org/10.1016/j.matdes.2011.04.057

11. Medeiros, V. N.; Araújo, E. M.; Maia, L. F.; Pereira, O. D. \& Arimateia, R. R. - Polímeros, 18, p.302 (2008)

12. Morales, A. R.; Cruz, C. V. M. \& Peres, L. - Polímeros, 20 , p.39 (2010). http://dx.doi.org/10.1590/S010414282010005000004

13. Agrawal, P.; Araújo, E. M. \& Mélo, T. J. A. - Polímeros, 21, p.383 (2011). http://dx.doi.org/10.1590/S010414282011005000062

14. Ray, S. S. \& Bousmina, M. - Macromol. Rapid. Commun., 26, p.1639 (2005).

15. Scaffaro, R.; Mistretta, M. C. \& La Mantia, F. P. - Polym. Degrad. Stab., 93, p.1267 (2008). http://dx.doi. org/10.1016/j.polymdegradstab.2008.04.008

16. González-Nuñez, R.; Padilla, H.; De Kee, D. \& Favis, B. D. - Polym. Bull., 46, p.323 (2001).

17. Yordanov, C. \& Minkova, L. - Eur. Polym. J., 39, p.951 (2003). http://dx.doi.org/10.1016/S0014-3057(02)00332-4

18. Yordanov, C. \& Minkova, L. - Eur. Polym. J., 41, p.527 (2005). http://dx.doi.org/10.1016/j.eurpolymj.2004.10.034

19. Lahor, A.; Nithitanakul, M. \& Grady, B. P. - Eur. Polym. J., 40, p.2409 (2004). http://dx.doi.org/10.1016/j. eurpolymj.2004.07.004

20. Filippi, S.; Yordanov, C.; Minkova, L.; Polacco, G. \& Talarico, M. - Macromol. Mater. Eng., 289, p.512 (2004). http://dx.doi.org/10.1002/mame.200300334

21. Jiang, C.; Fillipi, S. \& Magagnini, P. - Polymer, 44, p.2411 (2003). http://dx.doi.org/10.1016/S0032-3861(03)00133-2

22. Kusmono, W. S.; Mohd Ishak, Z. A.; Chow, W. S.; Takeichi, T.; Rochmadi . - Polym. Lett., 2, p.655 (2008). http:// dx.doi.org/10.3144/expresspolymlett.2008.78

23. Nanocor, Inc. - "Nanocomposites Using Nanomer® I.30T Nanoclay". Disponível em: <http://www.nanocor.com/ tech_sheets/N604.pdf>. Acesso em: maio 2011.

24. Yan, L-T. \& Sheng, J. - Polymer, 47, p.2894 (2006). http:// dx.doi.org/10.1016/j.polymer.2006.02.048

25. Shi, D.; Hu, G-H.; Ke, Z.; Li, R. K. Y. \& Yin, J. - Polymer, 47, p.4659 (2006). http://dx.doi.org/10.1016/j. polymer.2006.04.058 
26. Ray, S. S.; Pouliot, S. \& Bousmina, M. - Macromol. Rapid. Commun., 26, p.450 (2005).

27. Si, M.; Araki, T.; Ade, H.; Kilcoyne, A. L. D.; Fisher, R.; Sokolov, J. C. \& Rafailovich, M. H. - Macromolecules, 39, p.4793 (2006). http://dx.doi.org/10.1021/ma060125+

28. Hong, J. S.; Namkung, H.; Ahn, K. H.; Lee, S. J. \& Kim, C. - Polymer, 47, p.3967 (2006). http://dx.doi. org/10.1016/j.polymer.2006.03.077

29. Mehta, S.; Mirabella, F. M.; Rufener, K. \& Bafna, A. - J. Appl. Polym. Sci., 92, p.928 (2004). http://dx.doi. org/10.1002/app.13693

30. Hotta, S. \& Paul, D. R. - Polymer, 45, p.7639. http://dx.doi. org/10.1016/j.polymer.2004.08.059

31. Spencer, M. W.; Cui, L., Yoo, Y. \& Paul, D. R. - Polymer, 51, p.1056 (2010). http://dx.doi. org/10.1016/j.polymer.2009.12.047

32. Morawiec, J.; Pawlak, A.; Slouf, M.; Galeski, A.; Piornowska, E. \& Krasnikowa, N. - Eur. Polym.
J., 41, p.1115 (2005). http://dx.doi.org/10.1016/j. eurpolymj.2004.11.011

33. Psarski, M.; Pracella, M. \& Galeski, A. - Polymer, 41, p.4923 (2000). http://dx.doi.org/10.1016/S00323861(99)00720-X

34. Chiu, F. C.; Lai, S. M.; Chen, Y. L. \& Lee, T. H. - Polymer, 46, p.11600 (2005). http://dx.doi. org/10.1016/j.polymer.2005.09.077

35. Tung, J.; Simon, G. P. \& Edward, G. H. - Polym. Eng. Sci., 45, p.1606 (2005). http://dx.doi.org/10.1002/ pen. 20455

36. Lincoln, D. M.; Vaia, R. A.; Wang, Z-G.; Hsiao, B. S. \& Krishnamoorti, R. - Polymer, 42, p.1621 (2001). http:// dx.doi.org/10.1016/S0032-3861(00)00414-6

Enviado: 20/12/11

Reenviado: $31 / 05 / 12$

Aceito: $13 / 07 / 12$ 